\title{
Threshold Microsclerotial Inoculum for Cotton Verticillium Wilt Determined Through Wet-Sieving and Real-Time Quantitative PCR
}

\author{
Feng Wei, Rong Fan, Haitao Dong, Wenjing Shang, Xiangming Xu, Heqin Zhu, Jiarong Yang, and Xiaoping Hu
}

First, second, third, fourth, fifth, seventh, and eighth authors: State Key Laboratory of Crop Stress Biology for Arid Areas and College of Plant Protection, Northwest A\&F University, Yangling, Shaanxi 712100, China; and sixth author: Institute of Cotton Research of Chinese Academy of Agricultural Sciences/State Key Laboratory of Cotton Biology, Anyang 455100, China. Current address of X.-M. Xu: East Malling Research, New Road, East Malling, ME19 6BJ, Kent, UK. Accepted for publication 29 July 2014.

\begin{abstract}
Wei, F., Fan, R., Dong, H.-T., Shang, W.-J., Xu, X.-M., Zhu, H.-Q., Yang, J.-R., and Hu, X.-P. 2015. Threshold microsclerotial inoculum for cotton Verticillium wilt determined through wet-sieving and real-time quantitative PCR. Phytopathology 105:220-229.

Quantification of Verticillium dahliae microsclerotia is an important component of wilt management on a range of crops. Estimation of microsclerotia by dry or wet sieving and plating of soil samples on semiselective medium is a commonly used technique but this method is resource-intensive. We developed a new molecular quantification method based on Synergy Brands (SYBR) Green real-time quantitative polymerase chain reaction of wet-sieving samples (wet-sieving qPCR). This

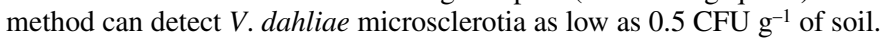
There was a high correlation $(r=0.98)$ between the estimates of con-

$>400$ soil samples were taken from the rhizosphere of individual plants with or without visual wilt symptoms in experimental and commercial cotton fields at the boll-forming stage. Wilt inoculum was estimated using the wet-sieving qPCR method and related to wilt development. The estimated inoculum threshold varied with cultivar, ranging from 4.0 and 7.0 CFU g ${ }^{-1}$ of soil for susceptible and resistant cultivars, respectively. In addition, there was an overall relationship of wilt incidence with inoculum density across 31 commercial fields where a single composite soil sample was taken at each field, with an estimated inoculum threshold of $11 \mathrm{CFU} \mathrm{g^{-1 }}$ of soil. These results suggest that wilt risk can be predicted from the estimated soil inoculum density using the new wet-sieving qPCR method. We recommend the use of 4.0 and 7.0 CFU g ${ }^{-1}$ as an inoculum threshold on susceptible and resistant cultivars, respectively, in practical risk prediction schemes.
\end{abstract} ventional plating analysis and the new wet-sieving qPCR method for 40 soil samples. To estimate the inoculum threshold for cotton wilt,

Verticillium dahliae Kleb. causes diseases on $>400$ plant species, including many crops of economic significance. Annual crop losses due to this pathogen are estimated to be in the billions of dollars worldwide $(23,34)$. Crop losses vary greatly among crops and among regions; crop losses may reach 80, 50, and $100 \%$ for cotton (34), potato (35), and lettuce (43), respectively. V. dahliae is a soilborne pathogen, which does not have a known sexual stage (23). It survives adverse environmental conditions by the formation of microsclerotia. Microsclerotia are composed of thickwalled and melanized cells which originate from hyphae through a process of budding (19). The primary inoculum of $V$. dahliae in soil is microsclerotia, fungal resting structures in dead plant tissues and in soil. Microsclerotia may survive for $>10$ years in the absence of hosts in soil (34).

Being a monocyclic disease, inoculum density in the soil at planting plays a critical role in the epidemiology of Verticillium wilt $(1,17,36,47)$. Even as little as $1 \mathrm{CFU} \mathrm{g^{-1 }}$ of soil can lead to significant wilt symptoms on cotton (33) and strawberry (17) in naturally infested soil and on artificially inoculated olive (29). Microsclerotia density of $V$. dahliae generally declines during the growing season but increases at harvest, with the release of microsclerotia into soil from damaged tissues of infected cotton plants

Corresponding authors: X.-P. Hu; E-mail address: xphu@nwsuaf.edu.cn; and X.-M. Xu; E-mail address: xiangming.xu@emr.ac.uk

* The $\boldsymbol{e}$-Xtra logo stands for "electronic extra" and indicates that the online version contains two supplemental figures.

http://dx.doi.org/10.1094/PHYTO-05-14-0139-R

(C) 2015 The American Phytopathological Society
Additional keywords: disease severity, proportional odds model.

(14). Incidence of Verticillium wilt is proportional to inoculum density in soil $(1,5,16,17,22,29,31,33,36,47)$; however, considerable variation occurs, with such a relationship depending upon crops and cultivars. Thus far, published studies $(1,5,17,22,33$, 36,47 ) have been focused on the relationship of inoculum density with wilt incidence at the population level, to predict wilt incidence of a given planting using the average inoculum density estimated for the field. However, there is a lack of information on this relationship at the level of individual plants (i.e., how is the probability of infection of individual plants related to inoculum density).

Benefits derived from different management options depend largely on the density of inoculum in the soil. Rapid and accurate quantification of inoculum density and the relationship of soil inoculum density to wilt development are essential for developing disease risk estimates and adopting specific management measures as necessary (16). In general, management options should be implemented at or before planting to prevent disease. Inoculum density can also be an important factor in determining the timing, nature, and duration of management practices. Several methods have been developed to quantify Verticillium spp. inoculum density in soil. The plating methods based on dry or wet plating are commonly used to quantify CFU based on semiselective medium, hence reflecting true infection potential. However, these methods are time (needing 6 to 8 weeks) and labor consuming (15).

Polymerase chain reaction (PCR) techniques provide a rapid way to detect and quantify the pathogen in soil. Competitive PCR, as a semiquantitative molecular method, was first developed to quantify $V$. dahliae in plant tissue $(8,27)$ and soil $(30)$. Real-time 
quantitative PCR (qPCR) provides opportunities for more accurate quantification of the pathogen in soil. Compared with the dry or wet sieving and plating method, qPCR has advantages in sensitivity, specificity, and speed. Several qPCR methods have recently been developed to quantify the Verticillium spp. inoculum density in soil $(2,6,9,45)$. These methods differ primarily in the primer design and DNA extraction methodology. Given the rapid nature of these methods in estimating inoculum density, it is now possible to routinely quantify inoculum density in commercial crop production. To better use these methods for decision making by the growers, it is important to determine the relationship between inoculum density and disease development for individual crops.

We attempted to use one published qPCR method (9) to quantify soil inoculum density and then use the estimates to develop a disease-inoculum relationship for cotton. However, this method failed to provide a reliable estimate of inoculum density around and below $1 \mathrm{CFU} \mathrm{g}^{-1}$ of soil. Other published methods $(2,6)$ cannot quantify inoculum density below $1 \mathrm{CFU} \mathrm{g}^{-1}$ of soil. Therefore, we developed and validated a new qPCR method with a modified method for DNA extraction from soil. Finally, we sampled soil from experimental and commercial fields to estimate soil inoculum density and then determined the probability of infection of individual plants in relation to inoculum density, and the relationship of overall wilt incidence with inoculum density in the field.

\section{MATERIALS AND METHODS}

Soil samples for estimating inoculum density. Soil samples were collected from two experimental fields (A and B) in 2012 and 2013 and three commercial production fields (C, D, and E) in 2013. At least 640 plants were assessed visually for wilt symptoms in each field at the time of soil sampling. Fields A and B, located in Henan province, China, were used for evaluating cotton cultivar resistance against $V$. dahliae (disease nursery); field A and $\mathrm{B}$ were artificially inoculated with the pathogen 15 and 20 years ago, respectively. Fields $\mathrm{C}, \mathrm{D}$, and $\mathrm{E}$ were commercial monoculture cotton production plantings, located in Shaanxi province, China; these three fields were cultivated by growers using standard cultural practices. In all five fields, two rows of cotton plants were grown on a single raised bed, with $60 \mathrm{~cm}$ between two rows, $80 \mathrm{~cm}$ between two beds, and 25 to $30 \mathrm{~cm}$ between plants within a single row. Two cultivars (susceptible 'Jimian11' [JM11] and resistant 'Zhongzhimian2' [ZHM2]) were sampled in both fields $\mathrm{A}$ and $\mathrm{B}$; cultivar identity in fields $\mathrm{C}, \mathrm{D}$, and $\mathrm{E}$ was uncertain, and hence referred to U_C, U_D, and U_E.

Because one of specific objectives was to establish a threshold of inoculum density for causing cotton wilt on individual plants, soil was sampled during late August to early September (the bollforming stage of cotton), instead of preplanting, from rhizosphere close to plants with and without wilt symptoms. Yield reduction is most closely related to wilt severity at the boll-forming stage (3) and wilt developed after this stage has negligible effects on lint production (36). Soil was sampled with a sampler $(2.5 \mathrm{~cm}$ in diameter) from a depth of $15 \mathrm{~cm}$ at four locations next to a plant (south, west, east, and north, $5 \mathrm{~cm}$ from the stem). At the same time, disease severity of the plant was recorded on a scale of 0 to 4 , where $0=$ no symptoms, $1=\leq 25 \%, 2=>25 \%$ and $\leq 50 \%, 3=$ $>50 \%$ and $\leq 75 \%$, and $4=>75 \%$ leaves with wilt symptoms (48). In total, 40 to 138 soil samples were taken from each field and, when possible, an equal number of soil samples were taken for each disease category.

To estimate the relationship between inoculum densities and wilt incidence, a composite soil sample was obtained from each of the 31 commercial fields in Shaanxi Province during the August-to-September period in 1994. In each field, soil was taken at 30 points ( 15 across each of the two diagonals) and then mixed together. At the same time, the incidence of plants with wilt symptoms was assessed on 200 individual plants selected randomly in each cotton field.

Estimating soil inoculum density using the wet-sievingplating method. The wet-sieving method described by Harris et al. (18) was used to estimate soil inoculum densities. Soil samples was first air dried for 3 weeks to kill conidia and mycelial fragments of $V$. dahliae until sieving (2-mm mesh) was possible (7). A sample of $20 \mathrm{~g}$ of soil was placed into a screw-cap bottle and filled to $100 \mathrm{ml}$ with distilled water. The suspension was broken down by vigorous agitation for $1 \mathrm{~h}$ on a reciprocating shaker (HS501; IKA, USA) operating at $175 \mathrm{rpm} \mathrm{min}^{-1}$, then washed through $20-\mu \mathrm{m}$ sieves (20 $\mathrm{cm}$ in diameter), and the residue on the sieve was recovered and dispensed into the original bottle and again filled to $100 \mathrm{ml}$ with distilled water. The sieves were thoroughly washed and rinsed between samples in an ultrasonic cleaning bath. The suspension was shaken thoroughly; then, aliquots of a 2-ml soil suspension were transferred individually with a wide-orifice pipette to each of 10 petri plates $(100 \mathrm{~mm})$ of modified soil extract agar (MSEA) medium. A glass spreader was used to distribute the 2-ml suspension over the agar surface. The plates were incubated at $22^{\circ} \mathrm{C}$ for 4 weeks in the dark, following which the soil was washed from the surface of the medium and the dishes were then left inverted to dry. After the agar had dried, plates were scanned for colonies of $V$. dahliae at $\times 24$ under a dissecting microscope (SMZ-10 Nikon, Japan).

Estimating soil inoculum density using wet-sieving qPCR method. A qPCR technique was developed to quantify soil inoculum levels using target DNA cloned in a plasmid (Supplemental Figure 1) as a standard because the stability of genome DNA or PCR product under long-term storage can deteriorate. This ensured that the same set of standards could be used over many runs. The relationship between target DNA copy number in plasmids and inoculum density (number of microsclerotia) was then established using two sets of samples with known numbers of DNA copy or microsclerotia; this relationship was used to convert the estimated DNA copy number to number of microsclerotia. Soil samples were initially treated as in the wet-sieving method (before plating) before DNA extraction. Soil samples with a wide range of inoculum density (as estimated by the wetsieving method) were used to validate the wet-sieving qPCR method.

Primer specificity. A primer pair specific to $V$. dahliae (forward Vd-F929-947: 5'-CGTTTCCCGTTACTCTTCT-3', and reverse Vd-R1076-1094: 5'-GGATTTCGGCCCAGAAACT-3') was designed from the high-copy-number intergenic spacer (IGS) of ribosomal DNA (6). This primer pair produced an amplicon length of $160 \mathrm{bp}$. Specificity of this primer pair was tested against $17 \mathrm{~V}$. dahliae isolates and a single isolate of several common soilborne pathogens: V. albo-atrum, Gibellulopsis nigrescens, Rhizoctonia solani, Fusarium oxysporum, F. solani, and Colletotrichum gossypii isolates (Supplemental Figure 2). All isolates were grown in potato dextrose broth for 14 days, and total genomic DNA was extracted from $\approx 100 \mathrm{mg}$ fresh weight of mycelium using the cetyltrimethylammonium bromide method (40). PCR amplification was performed in a total volume of $25.0 \mu \mathrm{l}$, containing $2 \mathrm{mM} \mathrm{MgCl}, 200 \mu \mathrm{M}$ each deoxynucleoside triphosphate, $0.2 \mu \mathrm{M}$ each primer, $50 \mathrm{ng}$ of DNA, and 1.0 unit of DNA polymerase (GeneAmp PCR System 9700). Amplification conditions were a denaturation step for $5 \mathrm{~min}$ at $94^{\circ} \mathrm{C}$ followed by 35 amplification cycles consisting of $30 \mathrm{~s}$ at $94^{\circ} \mathrm{C}, 30 \mathrm{~s}$ at $62^{\circ} \mathrm{C}$, and $30 \mathrm{~s}$ at $72^{\circ} \mathrm{C}$. A final extension step was performed for $7 \mathrm{~min}$ at $72{ }^{\circ} \mathrm{C}$. Amplified DNA fragments were separated on a $2.0 \%$ agarose gel.

Quantification of $V$. dahliae DNA copy number in plasmid. The $V$. dahliae-specific band in the agarose gel was purified using the Agarose Gel Extraction Kit (Roche Inc., Germany) and cloned into the pMD18-T vector (TaKaRa Biotechnology, Japan). The 
recombined vector was used to transform Escherichia coli DH5 $\alpha$ competent cells using the electro-transformation method (13). After cloning, 10 positive colonies from transformation were randomly selected, and each colony was recovered in a Luria-Bertani liquid medium supplemented with ampicillin at $100 \mu \mathrm{g} \mathrm{ml}$ following overnight incubation at $37^{\circ} \mathrm{C}$. The recombinant plasmid was extracted using Plasmid Miniprep Kit (Bioniga, USA). The confirmation of positive colonies involved restriction digestion with KpnI and HindIII. A further confirmation of the insert was carried out via sequencing (Shanghai Shenggong Biotechnological Ltd., Shanghai, China). The concentration of the plasmid was quantified using the NanoDrop 2000 Spectrophotometer (Thermo Fisher Scientific Wilmington, DE) and copy number was

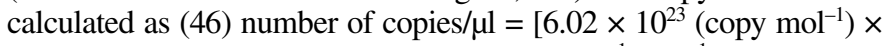
DNA amount $(\mathrm{g})] /\left[\mathrm{DNA}\right.$ length $\left.(\mathrm{dp}) \times 660\left(\mathrm{~g}^{-1} \mathrm{~mol}^{-1} \mathrm{dp}\right)\right]$.

A 10-fold dilution series of the plasmid DNA, ranging from $3.25 \times 10^{0}$ to $3.25 \times 10^{5}$ copies $\mu \mathrm{l}^{-1}$ (i.e., a total of six concentrations), was used to construct a standard curve in qPCR. Once prepared, this dilution series of standards was distributed into small portions in Eppendorf tubes and stored at $-40^{\circ} \mathrm{C}$ until use.

DNA extraction from soil. Initially, $20 \mathrm{~g}$ of air-dried soil was treated as in the wet-sieving method. The contents on the $20-\mu \mathrm{m}$ sieves were washed back into a centrifuge tube $(50 \mathrm{ml})$. The tube was then centrifuged at $8,000 \mathrm{rpm}$ for $5 \mathrm{~min}$ and the pellet was kept at $-60^{\circ} \mathrm{C}$ for $12 \mathrm{~h}$ in a vacuum freeze dryer (SIM, USA) before DNA extraction. Fungal DNA was extracted from a 10th of the contents. Each sample was placed in the provided 2-ml DNA extraction tubes containing lysing matrix $\mathrm{E}$ (which is a mixture of ceramic and silica particles to efficiently lyse all soil organisms), frozen in liquid nitrogen for $1 \mathrm{~min}$, and then placed in a Micro Homogenizing System (Tomy MS-100, Japan) at 5,000 rpm for $40 \mathrm{~s}$. These two steps were repeated once before addition of $978 \mu \mathrm{l}$ of sodium phosphate buffer and $122 \mu \mathrm{l}$ of MT nonfat milk and Tween 20, kit supplied, buffer. Total DNA of each soil sample was extracted using the FastDNA Spin Kit for Soil (MP BioMedical, USA) following the manufacturer's protocol, with the following modifications: (i) instead of letting the Binding Matrix settle, briefly centrifuging the tubes at $14,000 \times g$ and then removing the supernatant; (ii) washing the pellet by gently resuspending in $1 \mathrm{ml}$ of $5.5 \mathrm{M}$ guanidine thiocyanate (Sigma, USA), briefly centrifuging the tubes at $14,000 \times g$, then removing the supernatant until the silica returned to its original color; and (iii) after the last wash, resuspending the silica in $1 \mathrm{ml}$ of $5.5 \mathrm{M}$ guanidine thiocyanate before it was moved to a spin filter for centrifuging. The final elution volume of DNA was $50 \mu \mathrm{l}$.

qPCR conditions. The number of $V$. dahliae IGS copies was determined by SYBR Green real-time qPCR. Amplification reactions were performed in eight-well tubes using an ICycler instrument (iQ5; Bio-Rad Laboratories, Hercules, CA). The PCR reaction mixtures of $25.0 \mu \mathrm{l}$ contained $1.0 \mu \mathrm{l}$ of template DNA, $12.5 \mu \mathrm{l}$ of $2 \times$ UltraSYBR Mixture with Rox (ComWin Biotech, Beijing), $1.0 \mu \mathrm{M}$ each of the primer pairs, and $10.0 \mu \mathrm{l}$ of nanopure water. The amplification program consisted of initial denaturation of $10 \mathrm{~min}$ at $95^{\circ} \mathrm{C}$ followed by up to 40 cycles of $95^{\circ} \mathrm{C}$ for $30 \mathrm{~s}$, $62^{\circ} \mathrm{C}$ for $30 \mathrm{~s}$, and $72^{\circ} \mathrm{C}$ for $30 \mathrm{~s}$, with fluorescence monitored after each annealing step. Melting curve profiles were used to detect potential primer dimers and nonspecific amplification products. Amplicon melting profiles were obtained by increasing the reaction temperature from 55 to $95^{\circ} \mathrm{C}$. Plasmid DNA with the cloned target sequence was used as the positive control and standards, and sterilized nanopure water was used as the negative control. All samples in this study were amplified in quadruplicate.

Initial qPCR studies were performed in two technical replicates with no-template controls for all the series diluted standards at $-40^{\circ} \mathrm{C}$ after $0,7,14$, and 21 days to test the suitability and stability of cloned plasmid DNA. The relationship between DNA copy number and quantification cycle $(\mathrm{Cq})$ was determined by
iQ5 software 2.1 with the default settings. Consistency in the standards was calculated as $\mathrm{PV}=(100 \times|\mathrm{TCN}-\mathrm{ACN}|) / \mathrm{TCN}$, where PV is the relative quantification error and TCN and ACN are theoretical and quantified copy number, respectively. PV values $<10 \%$ indicate high stability (11).

Quantification of $\boldsymbol{V}$. dahliae microsclerotium number. Microsclerotia of $V$. dahliae were produced in vitro, as described previously (20). Strain JY was cultured in a modified basal agar medium at $\mathrm{pH} 11.5$ and at $20^{\circ} \mathrm{C}$, and incubated for 25 days in the dark to induce production of microsclerotia. Fungal cultures were comminuted with a blender (HR2839; Philips) in $200 \mathrm{ml}$ of tap water for four 10-s pulses, then filtered through nested 160- and $20-\mu \mathrm{m}$ sieves. The contents on the sieves were rinsed under tap water for $2 \mathrm{~min}$; the remaining contents on the bottom layer $(20 \mu \mathrm{m})$ were washed back into a beaker. The final preparation was washed off the sieves with 2 to $10 \mathrm{ml}$ of water and transferred into $1.5 \mathrm{ml}$ Eppendorf tubes. The tubes were centrifuged at $5,000 \mathrm{rpm}$ for $5 \mathrm{~min}$, and the supernatant was discarded. The remaining pellet was kept in a water bath at $47^{\circ} \mathrm{C}$ for 5 min to kill mycelia and conidia (32). The tubes were moved into vacuum freeze dryer (SIM) at $-60^{\circ} \mathrm{C}$ for $16 \mathrm{~h}$ to dry and then stored at $-20^{\circ} \mathrm{C}$ until use.

Two methods were used to establish the relationship of $\mathrm{Cq}$ with the number of microsclerotia. First, known numbers of microsclerotia were added to Verticillium-free soil (soil collected from a field that had been continuously cropped with wheat for many years and also autoclaved at $121^{\circ} \mathrm{C}$ and $115 \mathrm{kPa}$ twice for $45 \mathrm{~min}$ each). Microsclerotia stored at $-20^{\circ} \mathrm{C}$ were prepared in aqueous suspensions and spread onto the surface of $2.0 \%$ water agar plates; individual microsclerotia were picked up and counted under a stereomicroscope (SMZ-10 Nikon, Japan) using a dissecting needle. Appropriate numbers of microsclerotia $(0,1,2$, $10,20,100,200,400,1,000$, and 2,000) was added into $2 \mathrm{~g}$ of Verticillium-free soil; there were three replicates for each inoculum density (each with two quantifications $=$ technical replicates). Fungal DNA in these microsclerotia-amended samples was extracted as described above.

Second, 100,000 microsclerotia were added to $2.0 \mathrm{~g}$ of Verticillium-free soil and fungal DNA was extracted from this sample. A 10-fold dilution series was then obtained from the extracted DNA, equivalent to 0.5 to $50,000 \mathrm{microsclerotia} / \mathrm{g}$ of soil. For each diluted sample, there were three quantifications (technical replicates). Amplification efficiency (E) was evaluated by qPCR assay $E=10^{-m^{-1}}-1$, where $m$ is the slope when $\mathrm{Cq}$ value was regressed on fungal DNA or numbers of microsclerotia (both on the logarithmic scale).

Validation and use of the qPCR method. In all, 40 soil samples (with a wide range of inoculum densities as estimated by the wet-sieving-plating method) from field A and B were used to validate the qPCR method. Once validated, the qPCR method was used to estimate inoculum densities for all field soil samples collected in 2012 and 2013. Six standards of plasmid dilution were included in each plate; there were four technical replications per sample. For soil samples collected in 1994, inoculum density was estimated using the conventional wet-sieving method.

Data analysis. The qPCR data were analyzed with the iQ5 software (version 2.1) to generate amplification curves, standard curves, and melting curves. Regression analysis was then used to assess the relationship of inoculum densities estimated by the qPCR assay with the traditional wet-sieving method.

A cumulative logit model was used to model the wilt severity $\left(Y_{i}\right)$, which was recorded in five categories $(j=5) . Y_{i}$ follows a multinomial distribution with a parameter $\pi$; and $\pi_{i j}$ denotes the probability that $i$ th plant falls in the wilt score $j$. The cumulative probability is then defined as

$$
y_{i j}=P\left(Y_{i} \leq \mathrm{j}\right)=\pi_{i 1}+\ldots+\pi_{i j}
$$


A cumulative logit is defined as

$$
\begin{gathered}
\operatorname{logit}\left(y_{i j}\right)=\operatorname{logit}\left[P\left(Y_{i} \leq j\right)\right]=\ln \left\{P\left(Y_{i} \leq j\right) /\left[1-P\left(Y_{i} \leq j\right)\right]\right\}= \\
\ln \left\{\left[P\left(Y_{i} \leq j\right) / P\left(Y_{i}>j\right)\right]\right\}
\end{gathered}
$$

By definition, a cumulative logit does not exist for the last category of the response variable. A cumulative logit model is a regression model for a cumulative logit (39):

$$
\operatorname{logit}\left(y_{i j}\right)=\ln \left\{\left[P\left(Y_{i} \leq j\right) / P\left(Y_{i}>j\right)\right]\right\}=\alpha_{j}-\Sigma \beta_{k} x_{i k}
$$

where $x_{k}$ represents the $k$ th explanatory variate, $\beta_{k}$ the effect of $x_{k}$, and $\alpha_{j}$ the intercept for each cumulative logit. The regression part $\Sigma \beta_{k} x_{i k}$ is independent of $j$. The larger the value of $\Sigma \beta_{k} x_{i k}$, the higher the probability of $Y_{i}$ falling in a category at the upper end of the category scale. An example cumulative logit model with five categories is shown in Figure 1. For small and large $\Sigma \beta_{k} x_{i k}$ values, the response is likely to fall in the first $(j=1)$ and the last $(j=5)$ category. The $\alpha_{j}$ values determine the horizontal displacements of the curves. In the present study, there were five categories in the wilt severity $(0,1,2,3$, and 4$)$. There were two explanatory variates: cultivar and inoculum density; the former is a categorical variable and the latter is a continuous variable.

Equation 3 describes a linear relationship of the logit of the odds ratio of the response being below or above a particular category with explanatory variates. It is the extension of the common logistic model with only two possible outcomes (i.e., diseased or healthy). Thus, cumulative logit models are a class of generalized linear models, assuming that the errors follow a binomial distribution. This model satisfies

$$
\ln \left\{\frac{\operatorname{Pr}\left(Y_{i} \leq j \mid x_{1}\right) / \operatorname{Pr}\left(Y_{i}>j \mid x_{1}\right)}{\operatorname{Pr}\left(Y_{i} \leq j \mid x_{2}\right) / \operatorname{Pr}\left(Y_{i}>j \mid x_{2}\right)}\right\}=\beta\left(x_{2}-x_{1}\right)
$$

for all $j$ (i.e., proportional odds property; hence, it is also called a proportional odds model). Thus, $\beta$ estimates the change in the cumulative odds ratio (on $\ln$ scale) for one unit increase in the explanatory variate $x$.

For a more accurate estimation of an inoculum density threshold for causing wilt symptoms on individual plants, wilt severity score data were first converted to two outcomes (healthy or diseased). Then, a logistic model was fitted to this new data set assuming that errors follow a binomial distribution-this is essentially the same as the cumulative logit model but with only two categories (focusing on diseased or healthy only); for example,

$$
\ln p /[1-p]=\alpha+\Sigma \beta_{k} x_{k}
$$

A generalized $R^{2}$ was calculated from log-likelihood values to measure model goodness of fit (39). The CFU values were logarithmically transformed (on the natural base) before fitting cumulative logit or logistic models. All analyses were done in R. Fitting linear and cumulative logit models were carried out using the "lm" and "ordinal" packages, respectively. Model comparison was carried out by the nested modeling method. Model comparisons were based on the likelihood test among nested models.

\section{RESULTS}

A real-time PCR method for quantification of soil inoculum. The primer pair specifically amplified $V$. dahliae and produced a single peak at $78.5^{\circ} \mathrm{C}$ in melting curve analysis, and nonspecific products were not observed. Recombinant plasmids produced the expected 2,692- and 160-bp bands after digestion with KpnI and HindIII, corresponding to the plasmid backbone and insertion fragment, respectively. BLAST analysis of amplicon sequence in National Center for Biotechnology Information databases showed that it shared 99 to $100 \%$ homology with the IGS sequence of $V$. dahliae. The $\mathrm{Cq}$ values were linearly related to the log-transformed copy number $\left(3.25 \times 10^{0}\right.$ to $3.25 \times 10^{5}$ copies $\left.\mu^{-1}\right)$ of the inserted $V$. dahliae DNA fragment in plasmids (Fig. 2A). No amplification was observed with the negative control. When the qPCR method was used to estimate the number of microsclerotia in a dilution series from a single DNA extraction of $2 \mathrm{~g}$ of soil with 100,000 microsclerotia, Cq values were linearly related to the log-transformed microsclerotial number (Fig. 2B). Finally, when the qPCR was applied to soil samples with a known number of microsclerotia separately added to each sample, $\mathrm{Cq}$ values was also linearly related to the log-transformed microsclerotium number (Fig. 2C). The qPCR method successfully detected $V$. dahliae and quantified the DNA at the lowest inoculum density $\left(0.5\right.$ microsclerotia $\mathrm{g}^{-1}$ of soil, hereafter referred to as $\mathrm{CFU} \mathrm{\textrm {g } ^ { - 1 }}$ of soil), which was $\approx 100$ times more sensitive than the conventional PCR detection method (Fig. 3). In all three cases, fitted linear models accounted for $>98 \%$ of the total variability in $\mathrm{Cq}$ values. There was very little variability among technical or biological replicates except at very low DNA copy numbers (Fig. 2A). The amplification efficiency was very similar for the three sets of samples, 0.98 to 1.01, indicating that the FastDNA Spin Kit for Soil was able to remove the inhibitors that might interfere with fluorescence generated in the qPCR reaction. Based on the two standard curves (Fig. 2A and C), a simple linear model was derived to relate DNA copy $(y)$ and microsclerotium $(x)$ numbers: $y=48.429 \cdot x\left(R^{2}=0.95\right)$.

All the diluted standards of plasmid were stable when stored at $-40^{\circ} \mathrm{C}$ for up to 14 days, except the standard of 3.25 copies $\mu l^{-1}$ on day 14 (Fig. 4). When stored for 21 days, relative variation in the estimated DNA copy number was large $(>16 \%)$ for the two lowest concentrations.

Estimated CFU values for 40 samples from field A and B using the wet-sieving method ranged from 0 to $601 \mathrm{CFU} \mathrm{g}^{-1}$ of soil, with most samples (34) having $<50 \mathrm{CFU} \mathrm{\textrm {g } ^ { - 1 }}$ of soil. The correlation in the estimated CFU values between the wet-sievingplating method and the wet-sieving qPCR method was very high: $r=0.97$ when excluding those samples with $>50 \mathrm{CFU} \mathrm{g}^{-1}$ of soil (Fig. 5) and $r=0.98$ for all 40 samples. A simple linear model without intercept described the relationship between qPCR and the wet-sieving estimates of inoculum density (fitted to the 34 samples with $<50 \mathrm{CFU} \mathrm{g}{ }^{-1}$ of soil): $\mathrm{qPCR}=1.205( \pm 0.042) \cdot \mathrm{CFU}$

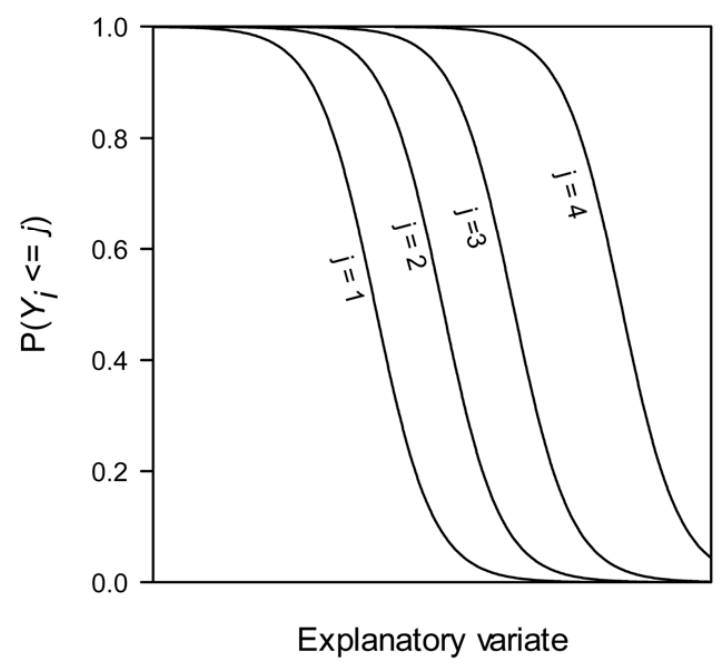

Fig. 1. Example curves illustrating cumulative logit models. This example describes a cumulative logit model with five categories for the response variable; the logit of the cumulative probability of the response variable linearly related to a set of explanatory variates. The four curves represent the cumulative probability of $P\left(Y_{i} \leq j=1,2,3\right.$, and 4) and the probability of the response variable in the category of $j=5$ equals to $1-P\left(Y_{i} \leq j=4\right)$. 
$\left(R^{2}=0.93\right)$, which was similar to the model fitted to all 40 samples $\mathrm{qPCR}=1.138( \pm 0.032) \cdot \mathrm{CFU}\left(R^{2}=0.96\right)$. However, because

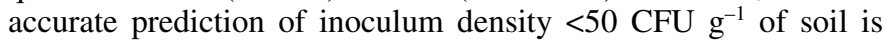
more important than predicting higher densities, the former qPCR CFU model was used in this study.

Relationship of disease severity with inoculum density. In total, 405 soil samples were collected from the five fields in 2012 and 2013: 138, 105, 82, 40, and 40 samples for JM11 (susceptible), ZHM2 (resistant), U_C, U_D, and U_E, respectively. Estimated CFU values ranged from 0 to 754 , with nearly $95 \%$ samples having $\mathrm{CFU}$ values $<100 \mathrm{CFU} \mathrm{g}^{-1}$ of soil (Fig. 6). The overall CFU level was the least for cultivar U_D and U_E; median CFU was $14.4,11.4,6.4,3.5$, and $3.2 \mathrm{CFU} \mathrm{g}^{-1}$ of soil for JM11, ZHM2, U_C, U_D, and U_E, respectively; the corresponding range (minimum to maximum) of CFU values was 0.0 to $600.9,0.0$ to $556.6,0.1$ to $754.2,0.2$ to 151.4 , and 0.0 to $255.6 \mathrm{CFU} \mathrm{g^{-1 }}$ of soil for the five cultivars. Overall, wilt was severe on JM11 and ZHM2, and was least on U_D and U_E (no plants with wilt score of 4 were found) (Fig. 7). Wilt incidence was $94 \%$ (field A JM11), 61\% (field A ZHM2), 92\% (field B JM11), and 24\% (field B ZHM2); wilt incidence was 56, 33, and $31 \%$ in the three commercial fields U_C, U_D, and U_E, respectively.

A cumulative logit model was satisfactorily fitted to the observed data; the generalized $R^{2}$ was $79 \%$. The logit of odds ratio

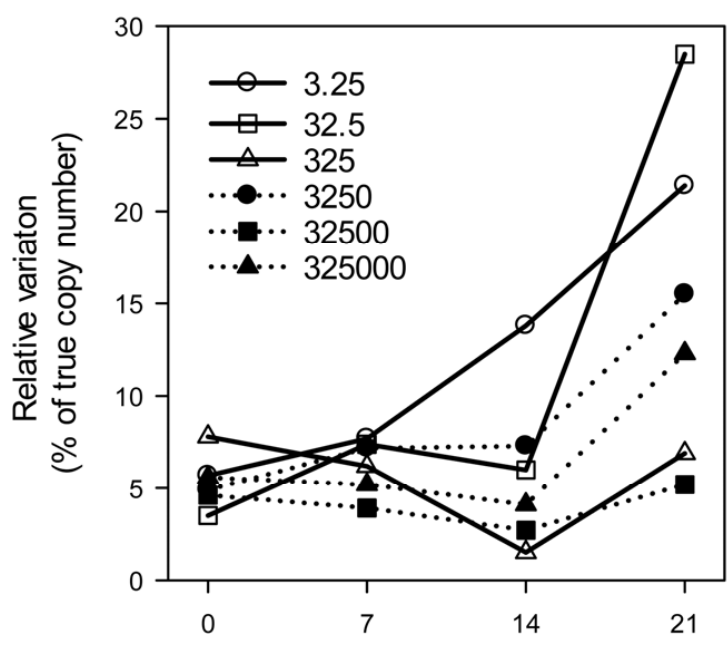

Days of storage at $-40^{\circ} \mathrm{C}$

Fig. 4. Relative variability in estimated copy number (expressed as percentage of the true copy number) of the target DNA in plastmid in relation to the length of time when plasmids were stored at $-40^{\circ} \mathrm{C}$. Relative variability was calculated as $\mathrm{PV}=|\mathrm{TCN}-\mathrm{ACN}| / \mathrm{TCN}$, where $\mathrm{PV}=$ percentage of variance, $\mathrm{TCN}=$ theoretical copy number, and $\mathrm{ACN}=$ actual copy number.
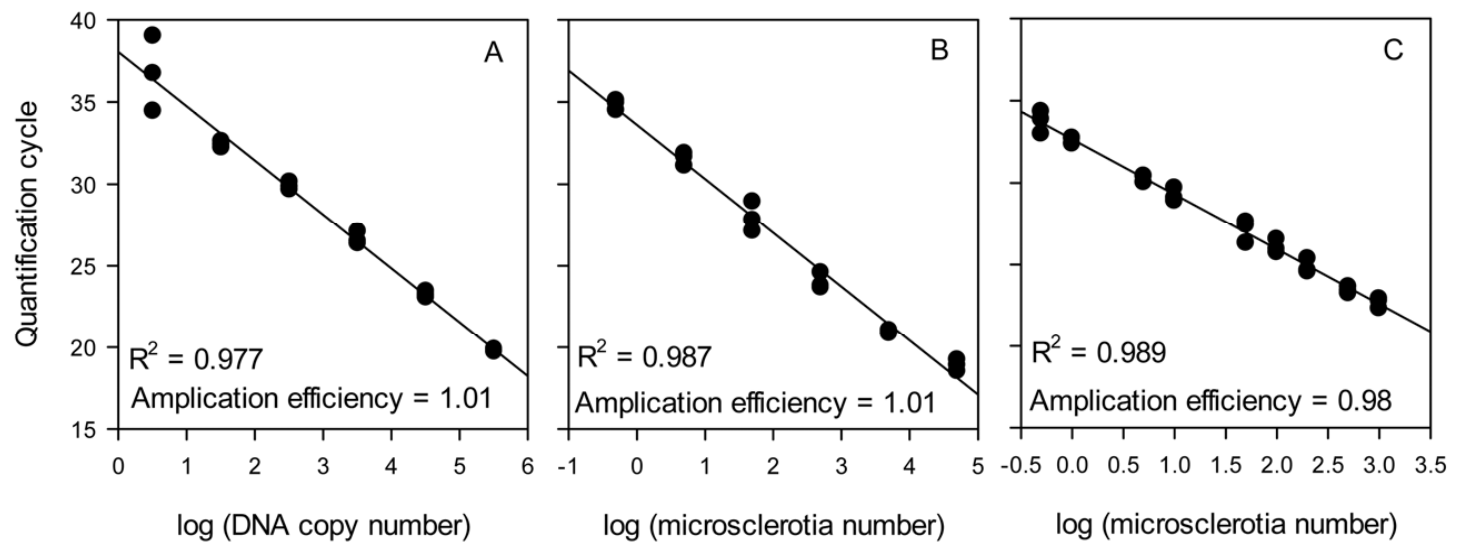

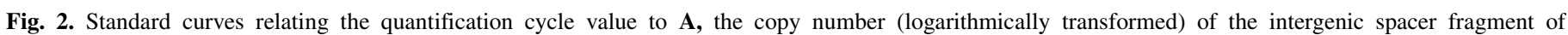

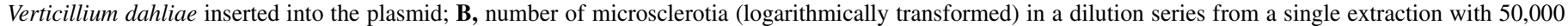
microsclerotia/g of soil; and $\mathbf{C}$, number of microsclerotia (logarithmically transformed) in a series of samples with different number microsclerotia added.

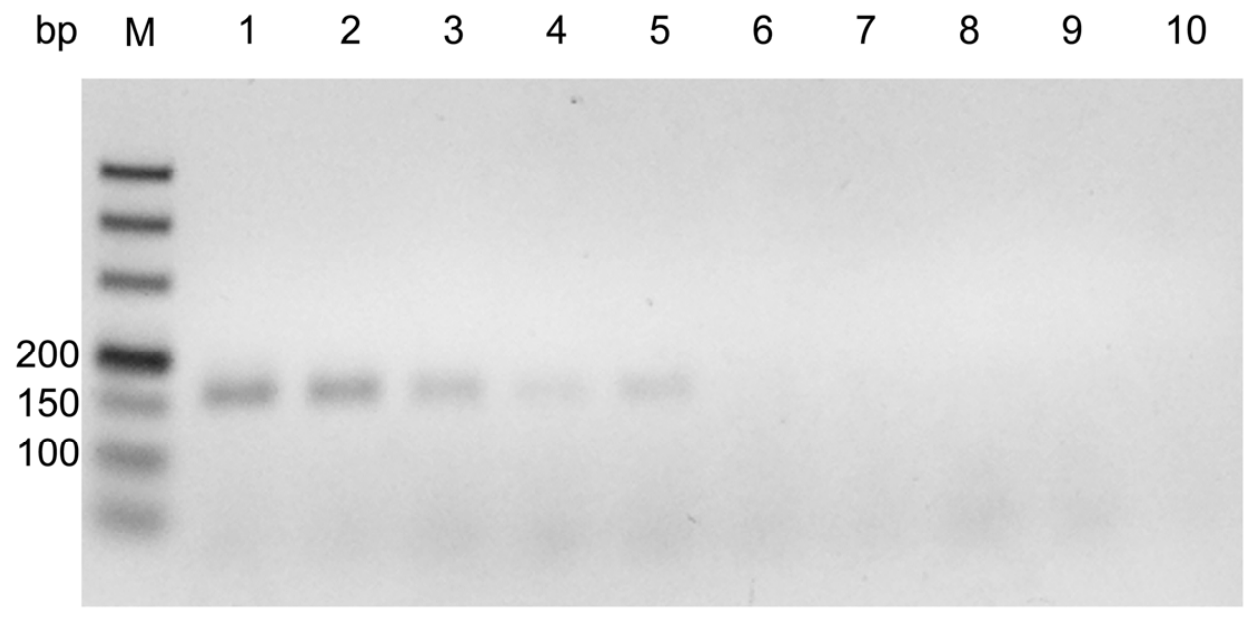

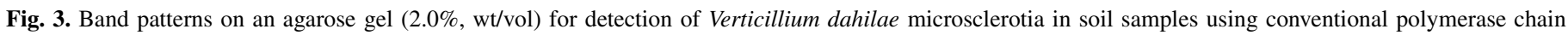

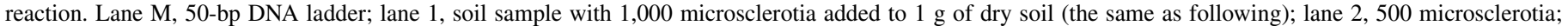

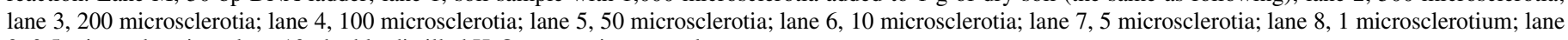
9, 0.5 microsclerotium; lane 10, double-distilled $\mathrm{H}_{2} \mathrm{O}$ as negative control. 
at a given disease score was linearly related to CFU values, with the exact relationship dependent on the cultivar. There were no significant statistical differences in the model parameters among three cultivars (ZHM2, U_D, and U_E), which differed from JM11 and U_C (Table 1). JM11 and U_C also differed significantly in the model parameters (Table 1). Fitted models indicated that wilt development on JM11 and U_C was more responsive to increases in the soil inoculum and that JM11 and U_C mainly differed in the last disease category (Fig. 8). At a given disease score, an increase of soil inoculum density by one unit (on the ln scale) increased the odds ratio for plants above the disease score by $\approx 54$ times (=exp(3.984); equation 4$)$ for JM11 and by $\approx 113$ times for U_C $(=\exp (4.729))$, compared with $\approx 9$ times $(=\exp (2.238))$ for the other three cultivars.

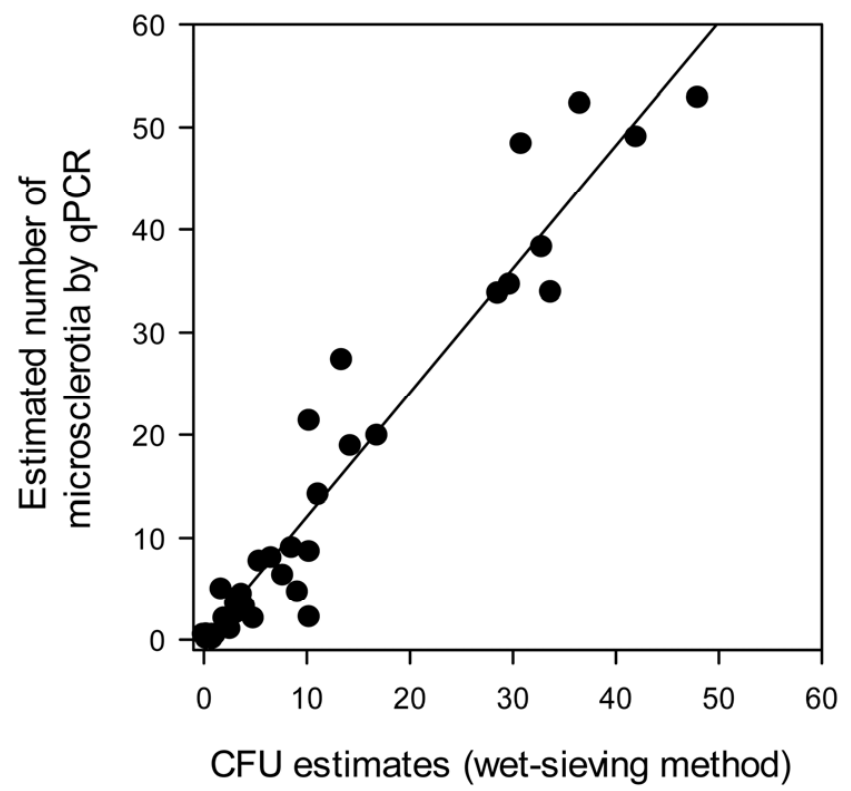

Fig. 5. Estimated inoculum density by the conventional wet-sieving method plotted against the new wet-sieving quantitative polymerase chain reaction (qPCR) method. Fungal inoculum was quantified in 40 soil samples from two fields using both the conventional and the new wet-sieving qPCR methods; of these samples, 34 samples had $<50 \mathrm{CFU} \mathrm{g}^{-1}$ of soil based one the conventional wet-sieving plating method. The solid line is the model fitted to the 34 samples: qPCR $=1.205( \pm 0.042) \cdot \mathrm{CFU}\left(R^{2}=0.93\right)$.
The parameter estimates for logistic models fitted to a simplified binary data set (diseased or healthy) are given in Table 1 . The generalized $R^{2}$ for the fitted logistic model was $\approx 62 \%$. As for the cumulative logit model, cultivars differed significantly in the model parameter estimates, though in a different manner from the cumulative logit model. U_D and U_E did not differ significantly, whereas the other three cultivars differed significantly in either the intercept or the slope parameter. Threshold values of inoculum densities for causing wilt on individual plants were estimated by setting the logistic model to zero (i.e., probability being infected is 0.5 ) and resulting estimates of threshold inoculum densities are also given in Table 1 . The threshold value was $\approx 4.0 \mathrm{CFU} \mathrm{\textrm {g } ^ { - 1 }}$ of soil for JM11, U_D, and U_E, whereas it was $\approx 7.0 \mathrm{CFU} \mathrm{\textrm {g } ^ { - 1 }}$ of soil for ZHM2 and U_C.

Wilt incidence was 0 to $64 \%$ among the 31 surveyed cotton crops whereas the estimated $\mathrm{CFU}$ was 0 to 14 . Increasing $\mathrm{CFU}$ values led to higher incidence (Fig. 9), which can be satisfactorily described by the logistic model $\ln p /[1-p]=-4.482+1.779 x$, where $p$ and $x$ are wilt incidence and CFU (ln-transformed), respectively. The fitted model is plotted together with the observed data (Fig. 9). The correlation between the fitted and observed incidence was 0.92 . Based on this model, a threshold CFU value for $50 \%$ wilt infection is estimated to be $\approx 11 \mathrm{CFU} \mathrm{g}^{-1}$ of soil.

\section{DISCUSSION}

Microsclerotia of $V$. dahliae in soil samples were quantified, combining conventional wet-sieving and SYBR Green I-based real-time qPCR (wet-sieving qPCR). This method proved to be sensitive and was able to detect 0.5 microsclerotia per gram of soil. The qPCR primer pair was also specific to V. dahliae and did not amplify other soilborne pathogens tested. Reliability of standards for qPCR is crucial (12) and a variety of materials have been used as standards, including PCR-amplified target sequences $(26,38)$, and plasmids containing the target sequences $(25,46)$. Dhanasekaran et al. (11) compared four types of commonly used standards: PCR products (with and without purification) and cloned target sequences (circular and linear plasmid) for their stability during storage. Cloned target sequences were noticeably more stable than PCR products. Therefore, unlike previous studies on quantification of $V$. dahliae DNA $(6,9,45)$, the present study used cloned target sequences in all quantification runs; these serial dilutions of recombinant plasmids appeared to be stable for up to 14 days at $-40^{\circ} \mathrm{C}$.

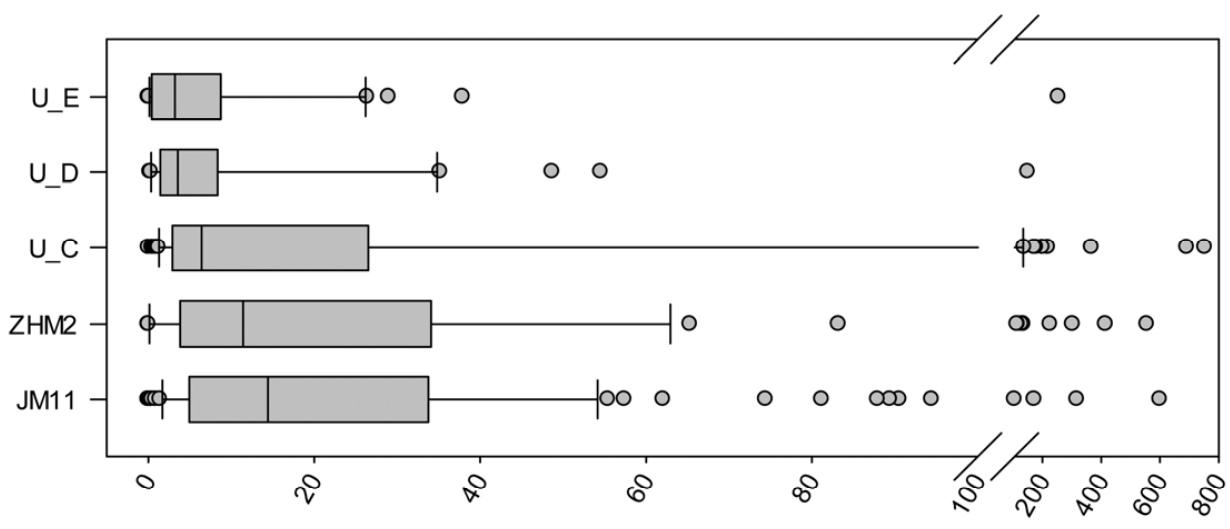

Estimated CFU by the qPCR method

Fig. 6. Boxplots of estimated CFU (by wet-sieving quantitative polymerase chain reaction [qPCR] method) of soil samples collected from five fields in China. Four soil core samples were taken from each plant, one in each direction (south, west, north, and east) $\approx 5 \mathrm{~cm}$ from the plant stem. Upper and lower limits of the box indicate the upper and lower quartiles of the distribution and the vertical line through the box indicates the median. The whiskers extending beyond the box indicate the range of 10th and 90th percentiles; outlying points are shown individually as circles. 
The present wet-sieving qPCR was able to detect wilt inoculum as low as $0.5 \mathrm{CFU} \mathrm{g}{ }^{-1}$ of dry soil. Limits of detection were 4.9 and 6.7 CFU g ${ }^{-1}$ of soil for a competitive PCR method (30) and a method based on SYBR Green qPCR (28), respectively. Recent

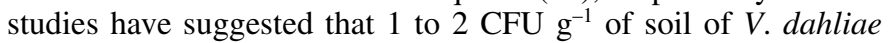
can be detected by a TaqMan probe and qPCR assay (6). A nested qPCR method was able to quantify $V$. dahliae inoculum as low as 1 CFU $\mathrm{g}^{-1}$ of soil (45). A SYBR green qPCR assay combined with sucrose flotation enabled detection of $V$. dahliae at $0.5 \mathrm{CFU}$ $\mathrm{g}^{-1}$ of soil (9). Unfortunately, we failed to use this method to consistently detect a low level of inoculum because of difficulties with the sucrose flotation. Thus, we combined the conventional wet-sieving method with qPCR to quantify $V$. dahliae inoculum in soil because wet-sieving was generally more effective in detecting $V$. dahliae and gave higher CFU counts than sucrose flotation (18). The high consistency and sensitivity of the wet-sieving qPCR method in quantifying $V$. dahliae inoculum, compared with previous techniques, are most likely attributable to increased recovery of microsclerotia through wet-sieving. The IGS primer may have also contributed to the increased sensitivity of the present qPCR method because there are $\approx 46$ copies of this region per haploid genome of $V$. dahliae (6).

As reported previously (6), there was a high correlation $(r>$ 0.96) between CFU estimates from the conventional wet-sieving and the new qPCR methods. However, CFU values determined by qPCR were slightly higher than that of the wet-sieving plating method: the ratio was 1.2 , which is significantly greater than 1.0. This systematic overestimation by qPCR might be attributed to two possible factors. First, the qPCR method may quantify fungal DNA from dead or dormant microsclerotia in the soil, although it is generally assumed that DNA from dead cells usually degrades fairly rapidly in natural, moist soil due to microbial activity (28). It is also possible that DNA of nonviable microsclerotia may persist in soil for a longer time. Second, wet-sieving plating methods may not be able to quantify all microsclerotia in a sample (44).

Because of the importance of the relationship between inoculum density and wilt incidence, such a relationship has been established on many hosts, including cauliflower (47), potato

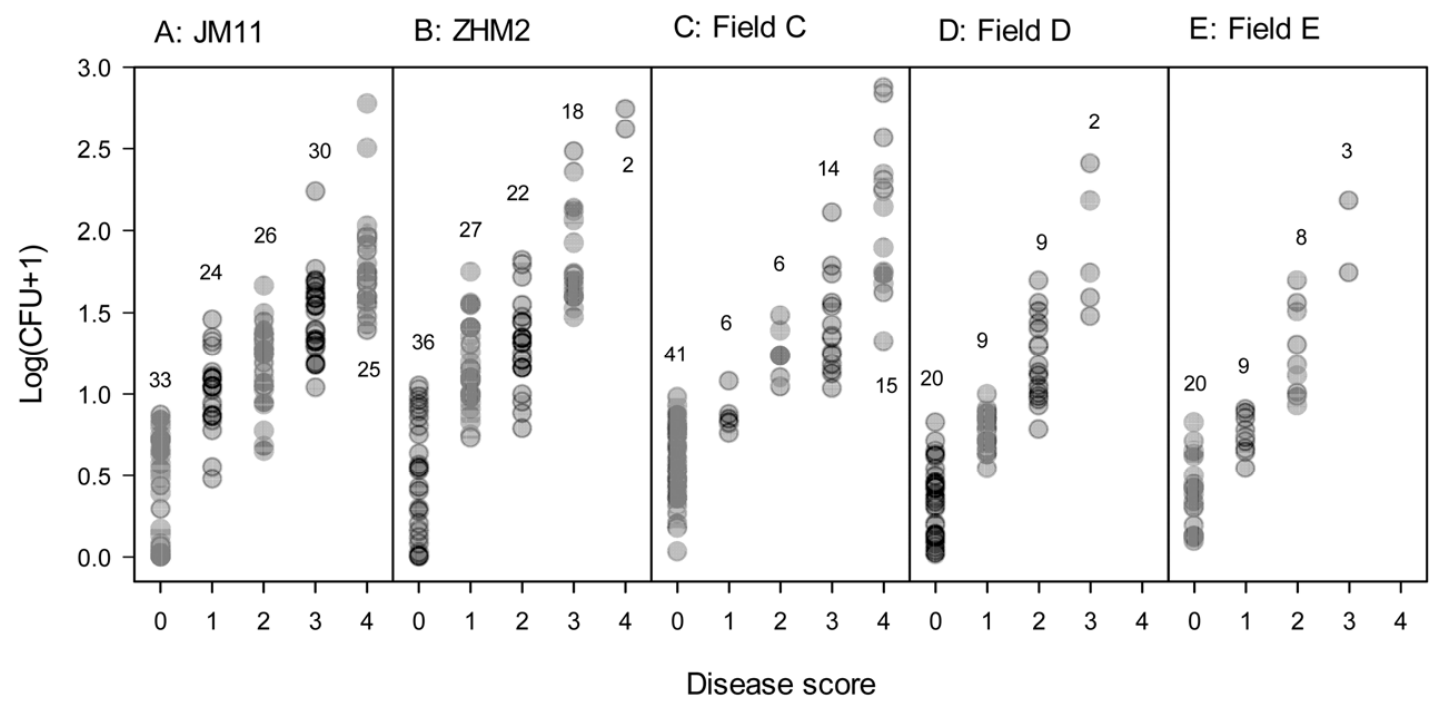

Fig. 7. Estimated inoculum densities of Verticillium dahliae by the wet-sieving quantitative polymerase chain reaction methods in soil samples from five fields (two in 2012 and 2013 [susceptible JM11 and resistant ZHM2] and three fields in 2013). Numbers are the number of plants (from which soil was taken) in each disease category: $0=$ no symptoms, $1=\leq 25 \%, 2=>25$ and $\leq 50 \%, 3=>50$ and $\leq 75 \%$, and $4=>75 \%$ leaves with wilt symptoms (48). The two fields in 2012 and 2013 were plots specifically designed for evaluating cotton resistance to wilt; two cultivars (JM11 and ZHM2) were sampled in both fields. The three other fields were commercial plantings with cultivar identity uncertain. The intensity of symbols represents the frequency of observations at that particular CFU value: the darker the symbol, the higher the frequency.

TABLE 1. Parameter estimates of a cumulative logit model and a logistic model fitted to the observed data, relating soil inoculum density of Verticillium dahliae (CFU g ${ }^{-1}$ soil, estimated by a quantitative polymerase chain reaction method) to wilt severity scores ( 0 to 4$)$ and binary data of wilt status of individual cotton plants, respectively ${ }^{\mathrm{a}}$

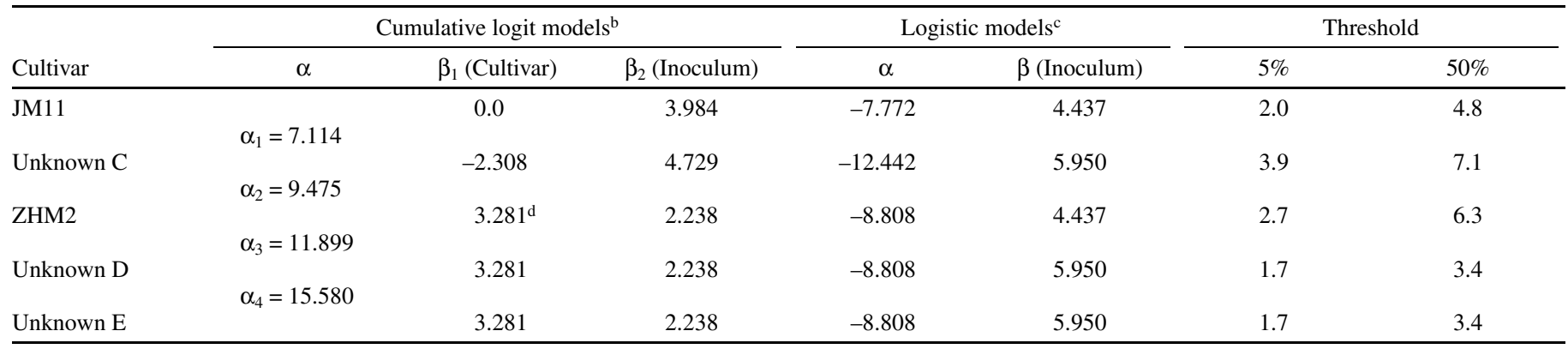

a In total, 405 samples were obtained in five fields. Inoculum values needed for 5 and $50 \%$ probability causing wilt symptoms in individual plants were estimated using the fitted logistic model.

${ }^{b}$ Parameters were defined in equation 4; $\alpha$ was the intercept for each cumulative logit (i.e., each disease score category except the last one: the fifth category); $\beta_{1}$ and $\beta_{2}$ are parameters representing the effects of cultivar and inoculum density (CFU g ${ }^{-1}$ soil) on the cumulative logit.

${ }^{\mathrm{c}}$ Parameters were defined in equation 5; $\alpha$ was the intercept and $\beta$ represents the effects of inoculum density (CFU g ${ }^{-1}$ soil) on the logit of the odds ratio of plants with wilt symptoms.

${ }^{\mathrm{d}}$ Parameters with the same value were estimated as a common parameter in modeling; the difference in parameter estimates between cultivars was statistically tested by the likelihood test based on the nested-models approach. 
(31), cotton $(33,36)$, strawberry (17), olive (29), eggplant (31), horseradish (22), artichoke (5), and nursery trees (16). There are also studies demonstrating that there is no direct correlation between wilt incidence and inoculum density $(4,10,41)$. Observed wilt-inoculum density relationships are often influenced by other factors, including environmental conditions, soil type, cultivar, and pathogen race or pathotype $(4,17,22,37,42)$. Thus, it is not surprising that wilt-inoculum density relationships in the present study were cultivar-dependent.

Of the five fields, inoculum densities were much higher in fields $\mathrm{A}$ and $\mathrm{B}$ (experimental plots) than the three commercial fields (U_C, U_D, and U_E), as expected. Reassuringly, the derived models describing density-wilt relationships depend on cultivar only, not on individual fields. The levels of inoculum densities in three commercial fields were similar to those values observed in previous studies on cotton $(4,7)$. This study estimated the threshold (50\% probability of infection) values of inoculum densities for causing wilt on individual plants of different cultivars. For susceptible cultivars, this threshold value was in the range of 3.4 to $4.8 \mathrm{CFU} \mathrm{g}^{-1}$ of soil and, for resistant cultivars, the threshold was in the range of 6.3 to $7.1 \mathrm{CFU} \mathrm{g}^{-1}$. A logistic model described the relationship between wilt incidence and inoculum densities in 31 commercial cotton fields, where disease incidence ranged from 0 to $64 \%$. To cause $50 \%$ wilt incidence, $\approx 11 \mathrm{CFU} \mathrm{g}^{-1}$ of soil is needed based on the fitted model, which is close to the estimated threshold value for resistant cultivars based on samples from individual plants. A greater uncertainty is expected for a population-based inoculum threshold estimate than one based on individual plants. Therefore, threshold values estimated based on individual plants should be used in predicting wilt risks in practice.

Classification of a cultivar being susceptible or resistant to wilt also depends on the wilt scale at which cultivar performance is assessed. When assessed over the whole disease severity spectrum, JM11 and U_C can be classified as susceptible and the other three as resistant. However, when assessed on a single disease score (i.e., healthy or diseased) based on the estimated inoculum threshold values, U_C may be regarded as resistant whereas U_D and U_E would be regarded as susceptible. This difference may have resulted from differential responses of cultivars to initial fungal infection and subsequent colonization. For instance, resistance of U_D and U_E may be expressed more in terms of restricting fungal colonization than preventing initial infection. Interestingly, wilt susceptibility classification of the two standard cultivars (JM11 and ZHM2) used in breeding evaluation trials was consistent between the two statistical criteria (cumulative logit model and simple logistic model).

All previously published results $(1,33,36)$ on the relationship of incidence with inoculum in cotton are derived from sampling at the population level. In contrast, the present study is based on the relationship between inoculum density and wilt development on individual plants; hence, the resulting threshold values are expected to be more reliable than those based on population sampling. This clear difference must be borne in mind when comparing the present results with previously published work. The inoculum density of $V$. dahliae required to cause $50 \%$ disease incidence on susceptible 'Acala' cotton was reported to be $5.0 \mathrm{CFU} \mathrm{g}^{-1}$ of soil (33). Inoculum density in May required for $50 \%$ disease in midSeptember was $\approx 19 \mathrm{CFU} \mathrm{g^{-1 }}$ of soil in cotton fields in California (36). When interpreting inoculum threshold value, the time of sampling also should be taken into account. There is a seasonal pattern in soil inoculum levels (24): they are highest at planting, progressively decrease during the cropping season, and eventually increase again postharvest in cotton. Similar inoculum dynamics have also been observed in V. longisporum in Sweden (21). The inoculum threshold may also be affected by aggressiveness of fungal strains present in the soil. It is well documented (4) in cotton that strains belonging to both nondefoliating and defoliating types occur among cotton fields. The strains in the defoliating type are more aggressive than the nondefoliating type (4). For a

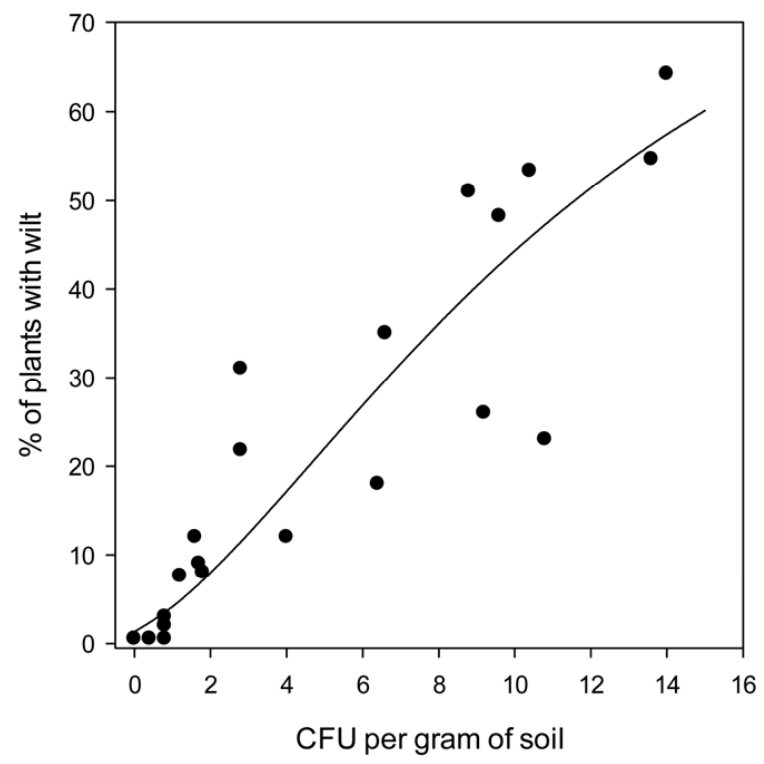

Fig. 9. Estimated inoculum density in each field by the conventional wetsieving plating method plotted against the incidence of cotton plants with wilt in 31 commercial cotton fields in China. The solid line is the fitted logistic model describing the relationship inoculum density (CFU) and wilt incidence.
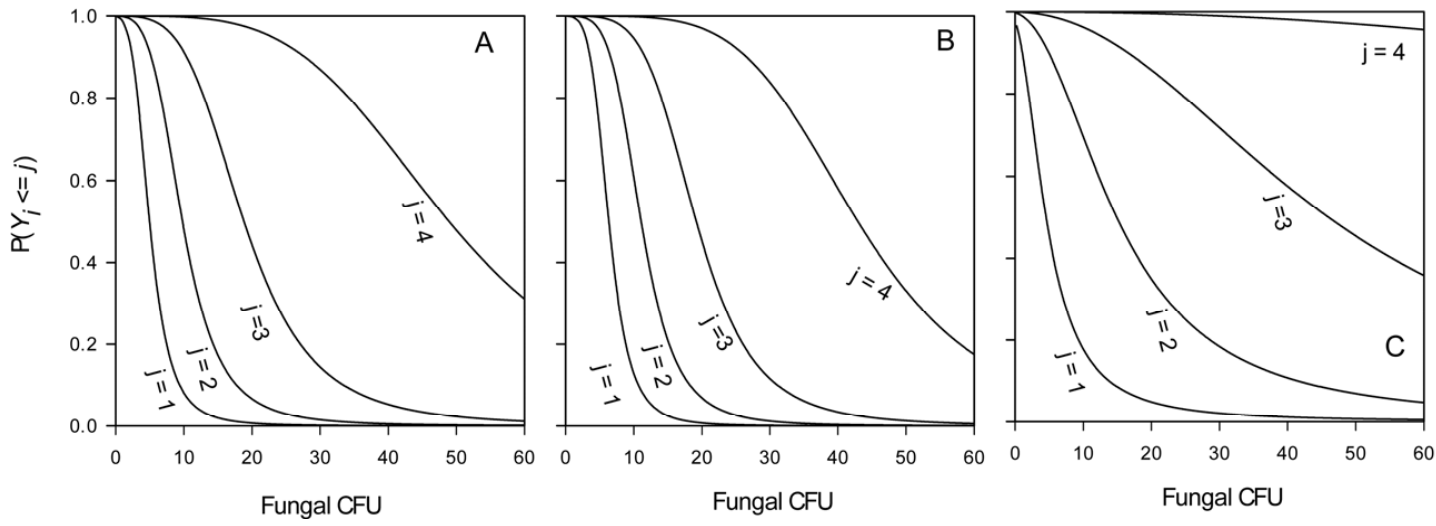

Fig. 8. Fitted cumulative logit models for cotton wilt scores ( 0 [no wilt] to 4 [severe wilt]) in relation to CFU values of Verticillium dahliae in soil estimated in August to September for three groups of cultivars: A, JM11; B, U_C; and C, ZHM2, U_D, and U_E. The four curves represent the cumulative probability of $P\left(Y_{i} \leq j=1,2,3\right.$, and 4$)$; that is, wilt score of $0,1,2$, and 3 and the probability of wilt score being 4 (i.e., category of $\left.j=5\right)$ equals to $1-P\left(Y_{i} \leq j=4\right)$. 
defoliating type isolate of $V$. dahliae, $\mathrm{CFU}$ in the range of 6 to 10 $\mathrm{CFU} \mathrm{\textrm {g } ^ { - 1 }}$ of soil may result in $100 \%$ disease incidence in highly susceptible 'Coker-310' cotton, whereas it needs $34 \mathrm{CFU} \mathrm{g^{-1 }}$ to cause a similar level of disease for the nondefoliating pathotype (4).

In summary, we have developed a new, wet-sieving qPCR method for quantification of $V$. dahliae microsclerotia combining the conventional wet-sieving method with SYBR Green I-based real-time qPCR method. This method can consistently quantify $V$. dahliae inoculum in soil at as low as $0.5 \mathrm{CFU} \mathrm{g}^{-1}$ of soil, which is sensitive enough for most research studies and practical applications. This is also the lowest detection limit among the assays currently available for $V$. dahliae. Using the method developed in this study, we quantified $>400$ soil samples for inoculum thresholds at the individual-plant level. The threshold values observed were close to 4.0 and $7.0 \mathrm{CFU} \mathrm{^{-1 }}$ of soil on susceptible and tolerant cotton cultivars, respectively. For application of these results in commercial production, however, a soil sampling scheme prior to planting, taking into account spatiotemporal variability in soil inoculum density, needs to be developed.

\section{ACKNOWLEDGMENTS}

We thank K. V. Subbarao for the presubmission review. The study was sponsored by NSFC (31371888), and partially by State Key Laboratory of Cotton Biology Open Fund (CB2013A20) and by the 111 project from Education Ministry of China (number B07049).

\section{LITERATURE CITED}

1. Ashworth, J. L. J., Huisman, O. C., Harper, D. M., Stromberg, L. K., and Bassett, D. M. 1979. Verticillium wilt disease of cotton: Influence of inoculum density in the field. Phytopathology 69:483-489.

2. Banno, S., Saito, H., Sakai, H., Urushibara, T., Ikeda, K., Kabe, T., Kemmochi, I., and Fujimura, M. 2011. Quantitative nested real-time PCR detection of Verticillium longisporum and $V$. dahliae in the soil of cabbage fields. J. Gen. Plant Pathol. 77:282-291.

3. Bassett, D. M. 1974. Resistance of cotton cultivars to Verticillium wilt and its relationship to yield. Crop Sci. 14:864-867.

4. Bejarano-Alcazar, J., Melero-Vara, J. M., Blanco-Lopez, M. A., and Jimenez-Diaz, R. M. 1995. Influence of inoculum density of defoliating and nondefoliating pathotypes of Verticillium dahliae on epidemics of Verticillium wilt of cotton in southern Spain. Phytopathology 85:14741481.

5. Berbegal, M., Ortega, A., Garcia-Jimenez, J., and Armengol, J. 2007. Inoculum density-disease development relationship in Verticillium wilt of artichoke caused by Verticillium dahliae. Plant Dis. 91:1131-1136.

6. Bilodeau, G. J., Koike, S. T., Uribe, P., and Martin, F. N. 2012. Development of an assay for rapid detection and quantification of Verticillium dahliae in soil. Phytopathology 102:331-343.

7. Butterfield, E. J., and Devay, J. E. 1977. Reassessment of soil assays for Verticillium dahliae. Phytopathology 67:1073-1078.

8. Dan, H., Ali-Khan, S. T., and Robb, J. 2001. Use of quantitative PCR diagnostics to identify tolerance and resistance to Verticillium dahliae in potato. Plant Dis. 85:700-705.

9. Debode, J., Van Poucke, K., Franca, S. C., Maes, M., Hofte, M., and Heungens, K. 2011. Detection of multiple Verticillium species in soil using density flotation and real-time polymerase chain reaction. Plant Dis. 95:1571-1580.

10. Devay, J. E., Forreste, L. L, Garber, R. H., and Butterfield. E. J. 1974. Characteristics and concentration of propagules of Verticillium dahliae in air-dried field soils in relation to prevalence of Verticillium wilt in cotton. Phytopathology 64:22-29.

11. Dhanasekaran, S., Doherty, T. M., Kenneth, J., and Grp, T. B. T. S. 2010. Comparison of different standards for real-time PCR-based absolute quantification. J. Immunol. Methods 354:34-39.

12. Dheda, K., Huggett, J. F., Bustin, S. A., Johnson, M. A., Rook, G., and Zumla, A. 2004. Validation of housekeeping genes for normalizing RNA expression in real-time PCR. BioTechniques 37:112-119.

13. Dower, W. J., Miller, J. F., and Ragsdale, C. W. 1988. High efficiency transformation of E. coli by high voltage electroporation. Nucleic Acids Res. 16:6127-6145.

14. Evans, G., Wilhelm, S., and Snyder, W. C. 1967. Quantitative studies by plate counts of propagules of the Verticillium wilt fungus in cotton field soils. Phytopathology 57:1250-1255.
15. Goud, J. C., and Termorshuizen, A. J. 2003. Quality of methods to quantify microsclerotia of Verticillium dahliae in soil. Eur. J. Plant Pathol. 109:523-534.

16. Goud, J. K. C., Termorshuizen, A. J., and Van Bruggen, A. H. C. 2011. Verticillium wilt in nursery trees: Damage thresholds, spatial and temporal aspects. Eur. J. Plant Pathol. 131:451-465.

17. Harris, D. C., and Yang, J. R. 1996. The relationship between the amount of Verticillium dahliae in soil and the incidence of strawberry wilt as a basis for disease risk prediction. Plant Pathol. 45:106-114.

18. Harris, D. C., Yang, J. R., and Ridout, M. S. 1993. The detection and estimation of Verticillium dahliae in naturally infested soil. Plant Pathol. 42:238-250.

19. Heale, J. B., and Isaac, I. 1965. Environmental factors in the production of dark resting structures in Verticillium albo-atrum, V. dahliae and $V$. tricorpus. Trans. Br. Mycol. Soc. 48:39-50.

20. Hu, X., Bai, Y., Chen, T., Hu, D., Yang, J., and Xu, X.-M. 2013. An optimized method for in vitro production of Verticillium dahliae microsclerotia. Eur. J. Plant Pathol. 136:225-229.

21. Johansson, A., Goud, J.-K. C., and Dixelius, C. 2006. Plant host range of Verticillium longisporum and microsclerotia density in Swedish soils. Eur. J. Plant Pathol. 114:139-149.

22. Khan, A., Atibalentja, N., and Eastburn, D. M. 2000. Influence of inoculum density of Verticillium dahliae on root discoloration of horseradish. Plant Dis. 84:309-315.

23. Klosterman, S. J., Atallah, Z. K., Vallad, G. E., and Subbarao, K. V. 2009. Diversity, pathogenicity, and management of Verticillium species. Annu. Rev. Phytopathol. 47:39-62.

24. Koroleva, N. S., Kas'yanenko, A. G., and Miller, V. R. 1986. Studies on the ecology, populations and evolution of Verticillium species. I. Population density dynamics of Verticillium dahliae Kleb. Mycol. Phytopathol. 20:509-512. (In Russian)

25. Lee, C., Kim, J., Shin, S. G., and Hwang, S. 2006. Absolute and relative QPCR quantification of plasmid copy number in Escherichia coli. J. Biotechnol. 123:273-280.

26. Leong, D. T., Gupta, A., Bai, H. F., Wan, G. Q., Yoong, L. F., Too, H. P., Chew, F. T., and Hutmacher, D. W. 2007. Absolute quantification of gene expression in biomaterials research using real-time PCR. Biomaterials 28:203-210.

27. Li, K. N., Rouse, D. I., Eyestone, E. J., and German, T. L. 1999. The generation of specific DNA primers using random amplified polymorphic DNA and its application to Verticillium dahliae. Mycol. Res. 103:1361-1368.

28. Lievens, B., Brouwer, M., Vanachter, A., Cammue, B. P. A., and Thomma, B. 2006. Real-time PCR for detection and quantification of fungal and oomycete tomato pathogens in plant and soil samples. Plant Sci. 171:155165.

29. Lopez-Escudero, F. J., and Blanco-Lopez, M. A. 2007. Relationship between the inoculum density of Verticillium dahliae and the progress of Verticillium wilt of olive. Plant Dis. 91:1372-1378.

30. Mahuku, G. S., and Platt, H. W. 2002. Quantifying Verticillium dahliae in soils collected from potato fields using a competitive PCR assay. Am. J. Potato Res. 79:107-117.

31. Nagtzaam, M. P. M., Termorshuizen, A. J., and Bollen, G. J. 1997. The relationship between soil inoculum density and plant infection as a basis for a quantitative bioassay of Verticillium dahliae. Eur. J. Plant Pathol. 103:597-605.

32. Nelson, P. E., and Wilhelm, S. 1958. Thermal death range of Verticillium albo-atrum. Phytopathology 48:613-616.

33. Paplomatas, E. J., Bassett, D. M., Broome, J. C., and Devay, J. E. 1992. Incidence of Verticillium wilt and yield losses of cotton cultivars (Gossypium hirsutum) based on soil inoculum density of Verticillium dahliae. Phytopathology 82:1417-1420.

34. Pegg, G. F., and Brady, B. L. 2002. Verticillium Wilts. CABI Publishing, New York.

35. Powelson, M. L., and Rowe, R. C. 1993. Biology and management of early dying of potatoes. Annu. Rev. Phytopathol. 31:111-126.

36. Pullman, G., S., and Devay, J. E. 1982. Epidemiology of Verticillium wilt of cotton: A relationship between inoculum density and disease progression. Phytopathology 72:549-554.

37. Rodriguez, E., Garcia-Garrido, J. M., Garcia, P. A., and Campos, M. 2008. Agricultural factors affecting Verticillium wilt in olive orchards in Spain. Eur. J. Plant Pathol. 122:287-295.

38. Rose'Meyer, R. B., Mellick, A. S., Garnham, B. G., Harrison, G. J., Massa, H. M., and Griffiths, L. R. 2003. The measurement of adenosine and estrogen receptor expression in rat brains following ovariectomy using quantitative PCR analysis. Brain Res. Protocols 11:9-18.

39. Schabenberger, O., and Pierce, F. J. 2001. Contemporary Statistical Models for the Plant and Soil Sciences. CRC Press, London.

40. Stewart, C. N., Jr., and Via, L. E. 1993. A rapid CTAB DNA isolation technique useful for RAPD fingerprinting and other PCR applications. BioTechniques 14:748-750. 
41. Strunnikova, O. K., Vishnevskaya, N. A., and Muromtsev, G. S. 1997. Abundance of mycelium and microsclerotia as indices of the soil status of Verticillium dahliae. Paper read at Seventh International Verticillium Symposium, Cape Sounion, Athens, Greece.

42. Subbarao, K. V., and Hubbard, J. C. 1996. Interactive effects of broccoli residue and temperature on Verticillium dahliae microsclerotia in soil and on wilt in cauliflower. Phytopathology 86:1303-1310.

43. Subbarao, K. V., Hubbard, J. C., Greathead, A. S., and Spencer, G. A. 1997. Verticillium wilt. In: Compendium of Lettuce Diseases. R. M. Davis, K. V. Subbarao, R. N. Raid, and E. A. Kurtz, eds. The American Phytopathological Society, St. Paul, MN.

44. Termorshuizen, A. J., Davis, J. R., Gort, G., Harris, D. C., Huisman, O. C., Lazarovits, G., Locke, T., Vara, J. M. M., Mol, L., Paplomatas, E. J., Platt, H. W., Powelson, M., Rouse, D. I., Rowe, R. C., and Tsror, L.
1998. Interlaboratory comparison of methods to quantify microsclerotia of Verticillium dahliae in soil. Appl. Environ. Microbiol. 64:3846-3853.

45. Wang, Y. L., Wang, Y., and Tian, C. M. 2013. Quantitative detection of pathogen DNA of Verticillium wilt on smoke tree Cotinus coggygria. Plant Dis. 97:1645-1651.

46. Whelan, J. A., Russell, N. B., and Whelan, M. A. 2003. A method for the absolute quantification of cDNA using real-time PCR. J. Immunol. Methods 278:261-269.

47. Xiao, C. L., and Subbarao, K. V. 1998. Relationships between Verticillium dahliae inoculum density and wilt incidence, severity, and growth of cauliflower. Phytopathology 88:1108-1115.

48. Zhang, W. W., Jiang, T. F., Cui, X., Qi, F. J., and Jian, G. L. 2013. Colonization in cotton plants by a green fluorescent protein labelled strain of Verticillium dahliae. Eur. J. Plant Pathol. 135:867-876. 